\title{
Jorge Andrade: uma polêmica
}

Elizabeth R. AZEVEDO ${ }^{1}$

Universidade de São Paulo - USP

Em recente encontro realizado em São Paulo para a comemoração dos noventa anos de nascimento do dramaturgo paulista Jorge Andrade $^{2}$, travou-se uma discussão em relação às críticas da montagem de Vereda da salvação no TBC em 1964. Discutiu-se se a desaprovação sofrida pela peça referia-se mais ao texto, por sua temática com forte carga social ou à encenação, sobretudo no que dizia respeito à direção de atores. Na verdade, esta é uma questão que há muito permanece no ar; e não por falta de reflexão a seu respeito, mas talvez pelo contrário. O crítico e professor Sábato Magaldi, que acompanhava de perto a realização da obra andradiana diz: "Não é simples definir-lhe as causas, e os depoimentos contraditórios apenas alimentam a confusão." (ANDRADE, 1970, p. 635). Sebastião Milaré, estudioso da obra de Antunes Filho, abre o capítulo relativo à montagem dizendo:

Vereda da salvação iluminou nosso teatro com as chamas sagradas da arte, atraindo bombeiros de todos os lados para extingui-las (...). Hoje, um quarto de século depois da estreia e curta temporada (...) continua sendo um ponto mal resolvido na memória teatral (...) foi um gesto revolucionário que, reprimido imediatamente, deixou marcas e resíduos ativos no organismo teatral. (MILARÉ, 1994, p.139)

Pretende-se aqui retomar tal discussão, apresentando informações sobre a trajetória antecedente dos envolvidos - o autor, o encenador Antunes Filho e a companhia do TBC - relembrando a situação de cada participante no momento da encenação e investigando a documentação de época referente às críticas publicadas ${ }^{3}$, a fim de tentar, se possível, contribuir com o debate.

Vereda da salvação foi encenada pelo Teatro Brasileiro de Comédia entre 8 de julho de 1964 e 27 de agosto do mesmo ano, com sessões duplas em vários dias. De autoria de Jorge Andrade, teve como encenador Antunes Filho, assistido por Stênio Garcia, música de Damiano Cozzella, cenários e figurinos de Norman Westwater. O elenco contava com as presenças de: Raul Cortez (Joaquim), Cleyde Yáconis (Dolor), Renato Restier (Manoel),

${ }^{1}$ Bacharel em História pela FFLCH/USP, professora de Teatro Brasileiro do Departamento de Artes Cênicas (CAC) da Escola de Comunicações e Artes da Universidade de São Paulo e coordenadora do Laboratório de Informação e Memória do CAC. Autora da tese: Recursos estilísticos na dramaturgia de Jorge Andrade (2002).

2 Jorge Andrade - 90 anos - (re)leituras.

${ }^{3}$ Devo lembrar que a recepção da peça também sofreu com avaliações circuladas informalmente. No entanto, estas são de difícil apreensão e estão reduzidas a uns poucos depoimentos, que serão, claro, considerados. 
Esther Mellinger (Artuliana), Aracy Balabanian (Ana), Stênio Garcia (Geraldo), Sylvio Rocha (Onofre), Lélia Abramo (Durvalina), Anita Sbano (Conceição), Ruth de Souza (Germana), José Antonio Sbano (Pedro), Yola Maia (Daluz), Marta Helena Araújo Ferreira, Fiorella, Roberto Azevedo, Potyguar Lopes, Eugênio Nascimento, José Pereira, Leilah Assunção, Carmem Pascal, Therezinha Mello, Regina Célia Rodrigues e Nair Araújo.

Jorge Andrade começara a escrever a peça mais de sete anos antes, baseado em um acontecimento real acontecido em abril de 1955: o massacre pela polícia de um grupo de trabalhadores rurais da Fazenda São João da Mata, evangélicos devotos da Igreja Adventista da Promessa, em Malacacheta, Minas Gerais. O texto apresenta em chave trágica a vida de um grupo de lavradores que, pela ocasião de comemoração da Semana Santa, conduzido pelo líder messiânico Joaquim, deixa-se levar por um tipo de histeria coletiva cometendo vários atos criminosos o que motiva seu extermínio sumário pelas autoridades. Imbricado com esse pano de fundo mais amplo, retrato da extrema miséria e falta de perspectivas em que vivem tais pessoas, tem-se o drama individual dos personagens centrais que jogam um papel fundamental no desdobramento dos acontecimentos.

Em 1957, Maria Isaura Pereira de Queiroz organizou, pela editora Anhembi, um livro sob o título de Estudos de Sociologia e História com artigos de diversos autores sobre os acontecimentos de Malacacheta, trazendo informações e análises sobre a situação econômica da região, a formação das fazendas, os sistemas de trabalho, a origem da igreja do Advento da Promessa, a psicologia de grupos e outros aspectos históricos e sociológicos envolvidos no conflito. A partir desses estudos, o dramaturgo conheceu melhor os acontecimentos e pode embasar seu trabalho. Dessas fontes parte das informações é transposta para o texto dramático: os nomes dos personagens (com exceção do de Dolor), a proximidade das biografias, os preceitos da seita, os crimes cometidos. Outros dados são, porém, alterados: relações de parentesco e conjugais, o destino de cada personagem - há alguns que não são mortos realmente como sugere o texto andradiano.

Importa que o resultado foi a criação de uma das maiores obras da dramaturgia brasileira moderna. Na avaliação de Sábato Magaldi (ANDRADE, 1970, p. 635) Vereda, a partir de um fato real, atinge estatura das grandes obras universais: "A leitura dessas pesquisas, feita com rigor científico, já sugere a admirável teatralidade das personagens e das situações dos reclamos e do rendimento cênicos. (...). Mais um fait divers que, na senda de Madame Bovary e O Vermelho e o Negro se transfigura em obra de arte.” 
Inicialmente, Jorge ofereceu o texto ao Teatro Cacilda Becker - TCB. Paulo Francis, diretor e crítico do Diário Carioca conta como foi esse contato, que acabou por nãoi se concretizar:

Jorge Andrade esteve no Rio onde veio entregar a Cacilda Becker o último ato de Vereda da salvação. Leu o texto para nós. (...) a impressão que nos ficou da leitura, entretanto, é que nada de comparável, em propósito e execução, existe na literatura brasileira contemporânea (não nos referimos apenas à dramaturgia). Vereda da salvação é uma das grandes peças do teatro moderno. $\mathrm{O}$ autor selecionou e orientou a linguagem do homem do interior, convertendo-a em poesia, sem perda da autenticidade realista. Dramatizou uma concepção de injustiça social, cuja válvula de escape é o fanatismo religioso, mantendo um equilíbrio perfeito entre a responsabilidade de cada indivíduo pelos seus atos e as circunstâncias que o levaram a cometê-los. (...) Mas Jorge ainda não terminou Vereda da salvação (...) $[\mathrm{O} \mathrm{TCB}]$ vai ter a rara oportunidade de fundir alta qualidade literária (sem quaisquer concessões) com consciência nacional, o que, afinal de contas, é o que todos desejamos para o teatro brasileiro. (FRANCIS: 1958)

Em julho de 1958, Jorge Andrade fez a primeira leitura da peça para o elenco do TBC, contudo o grupo da rua Major Diogo avaliou que não dispunha dos elementos necessários para encená-la e decidiu-se, com "grande entusiasmo", por outra peça do dramaturgo, escrita em parceria com Clô $\mathrm{Prado}^{4}$, Os vínculos, mas que também acabou não sendo levada à cena.

A versão, concluída em 1959, recebeu o primeiro lugar no concurso literário promovido pelo Instituto Nacional do Livro. Sabe-se, no entanto, que Jorge Andrade continuou a trabalhar na peça, mudando inclusive a estrutura central do drama ao inverter a ordem das cenas. A princípio a tentativa falhada de voo falhado empreendido por Joaquim e seus liderados acontecia no segundo ato, dos três que compunham a peça - o que transformava Joaquim no suspeito de encarnar o demônio. Esta versão difere bastante daquela apresentada nos anos 60, na qual os agregados se lançam ao voo num gesto desesperado para deixar este mundo de aflições sendo exterminados nesse momento, na cena derradeira da peça (que tem só dois atos), reforçando assim o alcance da denúncia social do texto. Ainda na avaliação de Magaldi (Idem), o texto, por ter sido discutido e avaliado ao longo de vários anos nos meios teatrais, acabou angariando "a fama de obraprima irrepresentável."

\footnotetext{
${ }^{4}$ Clô Prado, ou Clotilde Pereira da Silva Prado, dramaturga e colaborou em algumas peças com Jorge
} Andrade. 
A estreia, ainda que por uma companhia amadora, se deu na verdade em 1963, dirigida por Milton Bacarelli ${ }^{5}$ pelo Teatro Universitário de Pernambuco, recebendo excelente avaliação do crítico Valdemar de Oliveira:

Bem desejaria que ninguém se antecipasse a mim em louvar rasgadamente o espetáculo com que o Teatro Universitário de Pernambuco, ao encenar a peça Vereda da Salvação, de Jorge Andrade, atinge, em pleno: uma vigorosa maturidade artística. [...] Valha este registro, apenas, como uma nota prévia para uma análise mais detida do texto e do espetáculo, desde já incorporado às melhores páginas do nosso foral artístico. (...) Milton Baccarelli situou a tragédia moderna de Jorge Andrade, num espetáculo que tanto se distancia da demagogia barata quando se aproxima da dignidade artística. Enciclopédia Itaú Cultural de Teatro (OLIVEIRA, Jornal do Commercio, Recife, [s.p.], 29 e 31 de maio de 1963).

Mesmo antes dessa montagem, a peça também tinha estado nas considerações do diretor Antunes Filho para ser encenada por sua companhia, o Pequeno Teatro de Comédia. O PTC foi fundado por Antunes e esteve em atividades entre 1958 e 1962. Fora concebido a partir do modelo do TBC, na busca de um teatro de elevada qualidade artística e espírito de conjunto. Dele participaram: Felipe Carone, Armando Bógus, Nélson Duarte, Maria Dilnah, Nagib Elchmer, Luiz Eugênio Barcelos, tendo Ademar Guerra como diretor enquanto Antunes esteve na Europa.

Quando Vereda entrou em suas considerações, o diretor já havia montado, entre outras: O diário de Anne Frank, Plantão 21 e as Bruxas de Salém. Nesse período, Antunes perseguia o objetivo de dominar o realismo cênico, procurando superar aquele experimentado pelo teatro brasileiro de então, sobretudo no TBC, dominado por diretores italianos, e que haviam sido os mestres do diretor na sua primeira passagem pelo grupo de Zampari. Tal busca se justificava em um teatro no qual dar as costas ao público ainda era tido como um tabu:

Era uma marcação incomum: a protagonista ficar de costas! A resistência dos atores era muito grande - não só os atores mais antigos, também os jovens (...) Era por demais incomum. Antunes também revisa a posição 3X4, que determinados atores têm até hoje (...) (MILARÉ, 1994, p. 67).

Assim relembra Raul Cortez sobre as investidas de Antunes contra os estereótipos da interpretação. Antunes exigia mais dos atores. Exigia consciência do espaço onde

\footnotetext{
${ }^{5}$ Milton Bacarelli (São Paulo, 1930 - Maceió, 1994). Ator e diretor, foi professor na Universidade Federal de Pernambuco.
} 
atuavam, do próprio corpo, da voz, dos gestos, mas sobretudo consciência da ação que estavam realizando. Baseado fortemente em Stanislavski (apreendido através do cinema norte-americano), aliava as lições do mestre russo aos ensinamentos teóricos de Diderot (Paradoxo do ator - 1770/78). Segundo Ademar Guerra, seu assistente então, tudo o que Antunes realizava era muito mais intuitivo do que aplicação sistemática de um método préconcebido: "Usava Stanislavski, tenho certeza, sem conhecer Stanislavski direito. Ele intuía o processo. Antunes é um criador, não precisa de um método.” (MILARÉ, 1994, p. 68).

Milaré compara a busca pela "naturalidade" no PTC de Antunes Filho com a do Teatro de Arena, seu contemporâneo, apresentando este último como padecendo de uma visão marxista ingênua com propósitos utilitaristas da arte. A partir dos acirramentos das posições ideológicas da vida brasileira como um todo no início da década de 1960, tornouse necessário que Antunes assumisse uma estratégia de autodefesa diante de cobranças extra-artísticas.

Antunes procurava uma expressão cênica brasileira própria, mas, para tanto, ainda utilizava-se de textos estrangeiros. Antes de Vereda, passou por um texto menor, nacional, alcançando certo sucesso comercial (Alô!.. 36-5499, de Abílio Pereira de Almeida). A peça teve boas críticas que reconheciam o trabalho do diretor, assim como das que vieram em seguida: Pic-nic, de William Inge, e Plantão 21, de Sidney Kingsley. Com esses trabalhos Antunes seguia na pesquisa de um realismo artisticamente superior. A crítica $o$ acompanhava de perto nessa busca, como mostra a avaliação de Miroel Silveira para Plantão 21:

Isso [o fato da violência policial ser pouco mostrada realmente no palco durante a peça] não impede que a encenação de Antunes Filho não peque exatamente por esse defeito, o de buscar ilimitadamente ${ }^{6}$ o realismo. Sem muita consideração pelo fato de ser o palco uma convenção, no qual se "representa" o que na realidade inspirou, Antunes levou os intérpretes a um verismo absoluto, de que resultou a criação de uma atmosfera eletrizante entre palco e plateia que receava, às vezes, ser atingida pelas bofetadas que fartamente distribuíam no tablado. (apud MILARÉ, 1994, p. 85).

A busca por um realismo absoluto na interpretação dos atores se estendia também, segundo a crítica, a toda concepção cênica, acabando por dar início um método, embora ainda sem maior sistematização. Era o encontro da "veracidade humana", da "presença de gente" no palco. Havia, no entanto, um elemento básico nessas realizações do qual não se deve descuidar, o trabalho de Antunes com atores novos, que ainda não tinham adquirido nenhum dos tics da profissão. A eles se pediam exercícios baseados em cenas específicas do

${ }^{6}$ grifo da autora 
texto, tudo sempre sustentado por muita discussão sobre assuntos gerais que poderiam trazer informações e sugestões para os problemas enfrentados em cena.

O espetáculo escolhido para marcar sua volta da Europa foi As bruxas de Salem, de Arthur Miller, ainda no PTC. A ele Antunes aplicou os preceitos do teatro de Brecht e Piscator que passara a conhecer melhor. O texto, embora calcado no realismo psicológico que tanto marca o teatro norte-americano, foi submetido aos matizes do brechtianismo recém-absorvido, fazendo profissão de fé no poder do teatro para a conscientização política. Na avaliação de Sebastião Milaré (1994, p. 101), a visão de Antunes nesse momento encaminhava-se para

(...) extravasar na prática o acúmulo de teorias e propostas adquiridas nos últimos meses (...) Antunes usou o texto de Arthur Miller aleatoriamente, para servir não ao poeta, mas à sua ansiedade, ao seu desejo de materializar todas as hipóteses cênicas (...) tenta a harmonização do seu trabalho com a febre política que dominava o teatro.

Os críticos do período foram de opinião semelhante, condenando o espetáculo pelo que tinha de deslocado engajamento político, mas felicitando o diretor por, pelo menos, ter-se afastado dos textos mais comerciais sem maiores ambições artísticas.

O PTC finalizou sua carreira com uma peça menos ambiciosa como Sem entrada e sem mais nada, de Roberto Freire, mas na qual se experimentava procedimentos expressionistas. Assim, Antunes foi avançando na sistematização de seu método: “já não se trata de trabalhar os conteúdos internos e chegar à forma, mas partir desta para chegar àqueles. Com isso abre uma via de mão de dupla, entendendo que 'a ordem dos fatores não altera o produto". (MILARÉ, 1994, p. 114)

Antunes voltou ao TBC onde encenou Yerma, com alguns dos mesmos atores que estarão presentes nos papéis principais de Vereda: Cleyde Yáconis, Raul Cortez, Lélia Abramo e Stênio Garcia. A peça de Garcia Lorca levou Antunes pela vereda do teatro impregnado de poesia, de musicalidade e pelo universo popular eivado de primitivismo. No entanto, a peça fica pouco menos de dois meses em cartaz.

$\mathrm{O}$ TBC deu sequência a suas atividades com um texto nacional: $A$ revolução dos beatos, de Dias Gomes, que não foi suficiente para evitar que a crise financeira que já vinha ameaçando o grupo se instalasse. No início de 1963, diante de um apelo dos artistas do grupo, a Comissão Estadual de Teatro, presidida por Décio de Almeida Prado, consegue um aporte financeiro que dá sobrevida ao TBC. Monta-se então Os ossos do Barão, de Jorge Andrade, o maior sucesso da casa em todos os seus anos de existência. Diante do feito, 
uma nova peça do mesmo autor entra nas cogitações do diretor artístico, Maurice Vaneau. Assim, Vereda da salvação pode contar com um longo tempo de ensaios, ideal para as novas experimentações do diretor.

Segundo depoimentos de Vaneau ao jornal O Estado de S. Paulo, Vereda entrara novamente nas considerações do TBC desde 1962, tendo sido posta em ensaios, mas a crise financeira não tinha permitido que subisse à cena. Do Rio de Janeiro, o diretor e crítico Paulo Francis pareceu antever os acontecimentos:

A Vereda da salvação é outra peça importante a ser encenada pelo Teatro Brasileiro de Comédia, em direção de Antunes Filho. (...) Jorge Andrade me parece ter encontrado seu verdadeiro estilo como disse em outras oportunidades. A preocupação social do autor se alia a uma experiência essencial do indivíduo. (...) Mas vai além disso: analisa certas personagens até o fundo, fugindo da rotina sociológica do realismo. (...) O principal problema do texto é manter o equilíbrio entre essas duas componentes, a realista e a expressionista. $\mathrm{O}$ autor, do ponto de vista estilístico, conseguiu a unidade e o equilíbrio. Mas é outra coisa reproduzir isso no palco. Há sempre o risco de o diretor puxar mais para um lado, sendo que o componente expressionista está à beira do ridículo. (...) Vereda da salvação é a maior oportunidade de sua [Antunes Filho] carreira. É peça para provocar escândalo, artístico e social se for explorada em toda sua extensão. Pode ser um escândalo útil ao teatro brasileiro, sempre sob o risco de rotina e acomodação. (FRANCIS, 1962)

Para montagem de 1964, anunciou-se ${ }^{8}$ terem sido gastos quinze milhões de cruzeiros, o mais caro espetáculo do TBC em toda sua história, possibilitado pela temporada bem sucedida de Os ossos do Barão. Portanto, no momento em que Vereda começa a ser ensaiada, vários elementos estavam em jogo: a sobrevivência do TBC, o desenvolvimento do trabalho de pesquisa artística construído por Antunes nos últimos anos, o ambiente sócio-político brasileiro, pautado pela radicalização política e a mudança da temática tradicional da dramaturgia andradiana. Muitas incógnitas numa mesma equação.

Do ponto de vista do espetáculo, considerou-se que Vereda foi um marco divisório na história do teatro brasileiro. Vereda foi um gesto que "tirava nosso teatro do 'esforço modernizador' para inscrevê-lo entre as vanguardas que despontavam na cena internacional.” (MILARÉ, 1994, p. 128). Milaré faz em seu livro um rápido apanhado dessa cena internacional na qual insere a peça. Dos elementos mencionados, dois chamam a atenção: Jerzy Grotovski e Peter Brook, ambos retomando os caminhos indicados tempos

7 O Estado de S. Paulo, 26-6-1964

8 Idem. 
antes por Antonin Artaud. Além, claro, da vanguarda "oficial", representada pelo recémchegado teatro épico. Queimando etapas e realizando uma amalgama original e pessoal, Antunes apresentava o que chama de "ator-artista", no que seria uma espécie de versão laica do ator-santo grotoviskiano. Por outro lado, Carmelinda Guimarães (GUIMARAES, 1998, p. 33) nomeia seu capítulo referente à montagem de "a primeira ruptura", realçando na verdade o mergulho ainda mais profundo do diretor na estética stanislavskiana, afastando-se do "realismo de convenção" para atingir o "realismo integral", a busca do homem brasileiro, adequando o ator ao texto e não o contrário. (...) “tudo justificado teoricamente pelo livro de Maria Izaura Pereira de Queiroz, por sociólogos, tudo bem embasado" (DIONYSOS, 1980/25, p. 142).

Em depoimento ao jornal O Estado de S. Paulo, Antunes explicava que levava ao limite a noção da quarta parede, na busca de um verismo exacerbado, longe do "naturalismo internacionalmente consagrado buscando a verdade do nosso homem do campo" (O Estado de S. Paulo, 14-6-1964). "Eu parti da realidade, como se nós estivéssemos vendo alguém trabalhando, fazendo alguma coisa, como se você estivesse atrás de uma moita, assistindo" (DIONYSOS, 1980, p. 141) ${ }^{9}$. O próprio Antunes ressalta o início de uma renovação na interpretação, distinta do realismo romântico do Arena -

(...) era um protesto ao próprio Arena. (...) o Arena - ele foi criado depois contestou o TBC, e nós no TBC, depois, com Vereda da salvação, contestávamos o Arena como processo de interpretação. (...) Nós falávamos: "aqui, o Arena faria assim. Como é que eles fariam essa cena? Dessa maneira. Então nós vamos fazer desta outra maneira para contestálos.” (DIONYSOS, 1980,143)

$\mathrm{Na}$ verdade, nos depoimentos de época, só encontram-se referências ao "realismo", "naturalismo", "realidade". Matrizes vanguardistas mais bem definidas devem ser atribuídas a uma leitura a posteriori, mas não parecem ter sido explicitadas na época, embora se expressassem como um incômodo sentido pelos participantes do processo. Veja-se, por exemplo, a ideia de uma linha de encenação que se filiasse aos preceitos de um teatro pobre, dispensando a presença de cenários para potencializar o trabalho do ator:

Pergunta: um ator me disse exatamente isso: que o espetáculo perdeu na transposição para o palco. Resposta: É. E nós colocamos na cabeça que precisava dourar um pouquinho a pílula, fazer um pouco de cenário, e estragou tudo. Lá em cima, as pessoas iam assistir os laboratórios, que eram

\footnotetext{
9 Grifo da autora. A perspectiva lembra a ideia de "olhar pelo buraco da fechadura" ou "quarta parede"; mas "moita" se adequa melhor ao ambiente rural.
} 
uma coisa extraordinária, e se comoviam muito. E a gente inventou um termo, que depois o pessoal aplicava muito: antigesto, a antipalavra - não mais o gesto completando, ajudando a palavra, mas o gesto tendo outros sentidos, o da sobrevivência, e também a maneira de falar não ilustrava mais, não era mais pra ilustrar. (DIONYSOS, 1980, p. 142).

Em depoimento a Oswaldo Mendes, Ademar Guerra relembra o impacto causado por Vereda ainda em ensaios:

(...) E assisti ao ensaio. Quando terminou, eu estava chorando. Era o choro diante de uma coisa que me era nova e muito importante. Esse ensaio me marcou demais. Antunes conseguiu dar um retrato nosso pouco lisonjeiro, mas real. A nossa feiura, a nossa pobreza, a nossa burrice, a nossa insegurança. Isso na sala de ensaio. Quando desceu para o palco, o espetáculo glamourizou e perdeu a força. (MENDES, 1997, p. 47)

Anos depois, Antunes continuava a ter a mesma opinião: "Até hoje me arrependo de ter usado cenários. Mas imagine no palco sacrossanto do TBC fazer um espetáculo sem cenário!” (GUIMARÃES, 1998, p. 33). Aliás, essa foi uma concessão que não contribuiu em nada para o espetáculo uma vez que a crítica, quando o menciona, não o aprova. $\mathrm{O}$ crítico de O Estado de S. Paulo avaliou: "O cenário de Norman Westwater com seus barracos de madeira acotovelando-se e subindo pelo palco, lembra em demasia as favelas da nossa dramaturgia moderna.” (PRADO, 1964, p. 5)

Também Raul Cortez rememorava: "o cenário era totalmente oposto à ideia, à concepção da peça. Mostrou-se preso a um realismo bobo, quando a nossa encenação era mais para o mágico, mais para o lúdico, do que qualquer coisa realista ou naturalista." (apud ARANTES, 2010)

Jorge Andrade, por seu lado, apoiou totalmente a encenação e percebia a excepcionalidade da pesquisa: (...) "ter-se-á criado um realismo brasileiro que poderá vir a revolucionar a arte da representação no Brasil.” (O Estado de S. Paulo, 14-6-1964).

Da mesma forma como Antunes:

Hoje em dia eu vejo que foi esse o divisor de águas. Tem pouca gente que sabe disso, mas Vereda da salvação foi um divisor de águas, foi onde se fazia quase que um documentário, procurava fazer da ficção um documentário, uma coisa que depois, mais tarde, todo mundo tentou (...) O próprio Boal depois já fazia os Arenas contando alguma coisa, e já os atores andavam pelo chão [sic] (DIONYSOS, 25, p. 141). ${ }^{10}$

${ }^{10}$ A descrição dos exercícios criados por Antunes e seu assistente, Stênio Garcia, está em vários dos textos indicados na bibliografia. Eles receberam nomes como: lobo, árvore, caminhada, verme etc. 
Antunes parece atribuir as críticas mais à questão da encenação do que, propriamente, ao texto ou sua temática, “(...) foi um fiasco o espetáculo: foi um fracasso total porque era um código desconhecido de teatro, uma linguagem desconhecida de teatro" (DIONYSOS, 25, p. 141).

Do ponto de vista da tradição do estilo interpretativo que marcara o TBC, podemos invocar as irônicas declarações dadas por Abílio Pereira de Almeida sobre o novo processo criativo de Antunes:

(...) se mostrou entusiasmado com a nova técnica subsidiária de direção, adotada por Antunes Filho (...) tanto assim que está pensando em adotá-la para complementar a sua direção. O problema está em que tratando-se de 'Circulo de champagne', peça de luxo e riqueza, (...) a escolha das figuras de ginástica de despersonalização do intérprete terá um sentido diametralmente oposto. (...) ao invés de rastejarem pelo chão como vermes, em sua ginástica, se exercitarão nos movimentos e reflexos do bicho-da-seda. Quanto à figura da 'árvore', será substituída pela 'orquídea'. (...) O 'lobo', criado por aquele diretor, será substituído por 'poodle-caniche' (...).(O Estado de S. Paulo, 1964)

Além disso, as posições dos diretores mais jovens, engajados à esquerda, também não eram nada favoráveis ao espetáculo. Nesse caso, deve-se levar em consideração o quanto o momento político e o partidarismo vigente estavam por trás das avaliações estéticas:

(...) mas o que é importante é que nessa época todos nós - Boal, Flávio [Rangel], Zé Renato, Zé Celso, todo mundo - vivíamos brigando um com o outro (...) existia mesmo um bairrismo dentro do teatro: uma turma do lado de lá, a turma do lado de cá. Um não gostava do trabalho do outro, nunca! O Boal não gostava de espetáculo meu e eu jamais gostei de espetáculo dele, e o Zé Renato e o Flávio a mesma coisa. (DIONYSOS, 25, p. 143).

Poucas foram as críticas desfavoráveis ao texto. O crítico da Folha de São Paulo, apesar da avaliação da Bolsa de Teatro $^{11}$ - 93,7\% de ótimo e bom - tinha-o considerado mau, e visto como bom a peça Boing boing.

(...) detestamos a pretensiosa tragédia de Jorge Andrade, demagogicamente dirigida por Antunes Filho. (...) Nem a tragédia de Jorge Andrade imita uma ação elevada, nem logra a purgação de qualquer paixão. Cansa e aborrece o

\footnotetext{
11 A Bolsa de Teatro era organizada pela Folha de São Paulo desde os anos 50 e avaliava os filmes e peças de
} teatros apresentados em São Paulo. 
expectador. (...) Andrade está aflito com coisas suas, que a ninguém mais interessam e que ele não sabe transmitir. Se Jorge Andrade pecou pela pretensão, Antunes Filho errou por pura demagogia (...) a Europa transtornou-o. Antunes voltou crente de ter aprendido tudo (...) pseudorevolucionário, misturando tragédia clássica com teatro japonês, exercícios russos, mímica de Marcel Marceau e doses de frenesi coletivo (...). (CARVALHAES,1964)

Entretanto, no geral, reconheceu-se a qualidade do texto e a sua importância para a dramaturgia nacional. Registrou-se também que não se tratava de um panfleto político, no sentido mais demagógico desses termos. A poesia da linguagem, o desenvolvimento da estrutura, a construção psicológica dos personagens centrais, impressionaram os especialistas. Décio de Almeida Prado avaliava:

(...) Vereda da salvação resolve com inteligência as dificuldades próprias do teatro realista: nada pôr na boca das personagens que não lhes possa ser verossimilmente atribuído e, apesar disso, exprimir a totalidade do pensamento do autor, que consiste não só em narrar mas também em julgar os fatos. (...) A posição de Jorge Andrade nesse ponto [sobre o misticismo dos personagens], é a mesma de Euclides: profundo respeito pelo fanatismo, não pelo que é, mas pelo que representa socialmente, como expressão de um Brasil sofrido, obscuro, primitivo, e por isso mesmo singularmente representativo (...) Qual o sentido político de Vereda da salvação? Nenhum, na acepção restrita da palavra (...) é nitidamente uma peça de reivindicação social. Não aponta soluções - nem caberia faze-lo - mas de qualquer forma lança um apelo corajoso a todos nós que temos outras 'veredas da salvação' que não um beco sem saída, contido em seu sangrento desfecho. (PRADO, 1964, p. 294)

A polêmica criada em torno do espetáculo foi capitalizada pelo TBC. Nos anúncios na sessão de teatro dos jornais, as chamadas são feitas em princípio como "obra-prima de Jorge Andrade", depois "drama esmagador", mais adiante "cruel, violento, chocante"; isto é, a busca pelo sucesso de escândalo. E ele não foi pequeno. Ademar Guerra descreve a estreia e as forças políticas envolvidas na polêmica:

$\mathrm{Na}$ noite de estreia, vaias estrondosas. Lembro-me do genial, maravilhoso e lindo Flávio Império, que Deus o tenha! De pé, na mesma fileira que eu, vaiando, vaiando, vaiando... O espetáculo foi massacrado pela esquerda e pela direita. Eu entendo isso pelo que acabei de dizer: Antunes nos mostrou o nosso rosto verdadeiro. Sem falar que havia também um grande preconceito em relação ao autor, Jorge Andrade, que era de uma família rica de fazendeiros, como se ele não pudesse escrever sobre aquela gente miserável de Vereda da salvação. (MENDES, 1997, p.47) 
Ao longo da temporada as manifestações da plateia perduraram, segundo o depoimento de Sábato Magaldi: “(...) dos poucos espectadores presentes cada noite, fora alguns que saíam ostensivamente da plateia, ao fim da primeira parte, a maioria se demorava em aplausos, numa completa adesão” (apud MILARÉ, 1994, p. 141).

No drama que escreveu a seguir, Rasto atrás, e republicou em 1970 com algumas modificações, Jorge Andrade fez referências aos incidentes de Vereda numa espécie de autocrítica:

LAVÍNIA: Sua peça não fracassou. Só porque meia dúzia de idiotas não compreendeu você, não justifica que julgue seu trabalho um fracasso.

VICENTE: Você está invertendo os dados. Foi meia dúzia que me compreendeu. E minha peça contava verdades de nossa gente. Verdades que presenciei quando morava na fazenda. Cada pessoa quando saía do teatro, fazia-me sentir como se meu trabalho fosse gratuito, inútil (...) (ANDRADE, 1970, p. 460).

Como se viu, as críticas parecem ter se concentrado sobre a direção do espetáculo, na desaprovação do tipo de realismo radical, pouco "romântico", ou convencional, que Antunes buscava, na forma como trabalhou com os atores os resultados aos quais chegou.

A direção da Antunes Filho padece de um mal que já afligiu outras encenações de peças de Jorge Andrade: o desejo de se mostrar à altura, de replicar e duplicar em cena as dimensões e ambições épicas do texto. (...) as suas faltas são mais excessos do que deficiências. A tentação constante de todo o teatro moderno, a estilização, veio entretanto, toldar a pureza do projeto original. (PRADO, 1964, p. 294)

A crítica de Yan Michalski para o Jornal do Brasil reforça o ponto de vista que a encenação "atrapalhou" o texto

(...) Antunes Filho se perdeu e acabou prejudicando a montagem. Tivemos a impressão de que o diretor, em vez de estudar objetivamente o fenômeno dessa explosão mística, deixou-se levar por ela e, acrescentando um ângulo místico da interpretação ao próprio assunto do misticismo, desvirtuou em parte o sentido da obra (...) uma rubrica no início da peça diz: 'quando se abre o pano, Arturiana está parada à porta do seu casebre'. No espetáculo, quando se abre o pano, Arturiana está deitada na mata, esfregando-se no chão como um bicho. Esta incapacidade de ser simples, esta falta de economia de meios, este exagero tanto na interpretação quanto na marcação, prejudicam infelizmente uma obra de inegável seriedade e que poderia ter atingido um nível excepcional. (apud MILARÉ, 1994, p. 158) 
Dos registros que ficaram sobre Vereda da salvação parece emergir a avaliação de que a encenação de Antunes Filho potencializou a amplitude do texto andradiano de maneira insuspeitada. Embora aprovada pelo próprio autor, que quebrava assim sua ligação com a tradição do $\mathrm{TBC}^{12}$, a maior parte da crítica viu como exageradas as novidades trazidas pela interpretação dos atores. O espetáculo certamente causou desconforto estético e político, mas configurou-se como um marco fundamental nas trajetórias do autor, do diretor e do teatro brasileiro como um todo.

\section{BIBLIOGRAFIA CITADA:}

ANDRADE, J. Marta, a árvore e o relógio. São Paulo, Perspectiva, 1970.

ASSOCIAÇÃO MUSEU LASAR SEGALL. Nossos autores através da crítica. vol.2. São Paulo, Museu Lasar Segall, 1981.

AZEVEDO, E. R. Recursos estilísticos na dramaturgia de Jorge Andrade. 2002. Tese (Doutorado em Artes Cênicas). São Paulo, USP/ECA.

CARVALHAES. Sobre Vereda da salvação. Folha de São Paulo, 10-07-1964, Ilustrada, p.5.

DIONYSOS, São Paulo, 1980, n.25.

FRANCIS, Paulo. Diário Carioca. Rio de Janeiro, 28-05-1958.

. Diário Carioca. Rio de Janeiro, 3-12-1958.

. Diário Carioca. Rio de Janeiro, 18-8-1962.

FOLHA DE SÃO PAULO. Exercícios. São Paulo, 19-06-1964.

GUIMARÃES, Carmelinda. Antunes Filho: um renovador da cena nacional. Campinas, Ed. Unicamp, 1998.

GUZIK, Alberto. TBC: crônica de um sonho. São Paulo, Perspectiva, 1986.

Enciclopédia Itaú de Teatro Brasileiro Contemporâneo.

http://www.itaucultural.org.br/aplicexternas/enciclopedia_teatro/index.cfm

MENDES, Oswaldo. Ademar Guerra: o teatro de um homem só. São Paulo, Senac, 1997.

MILARÉ, Sebastião. Antunes Filho e a dimensão utópica. São Paulo, Perspectiva, 1994.

PRADO, Décio de Almeida. Teatro em progresso - crítica teatral (1955-1964). São Paulo, Marins Fontes, 1964.

QUEIROZ, Maria Isaura de. (org.) - Estudos de sociologia. São Paulo, Anhembi, 1957.

Abstract: This paper retrieves the discussions about the staging of Jorge Andrade's play Vereda da Salvação by Brazilian Comedy Theatre, that occurred between July and August 1964.

Keywords: Jorge Andrade; Vereda da salvação; Antunes Filho.

${ }^{12}$ E partia para a composição de textos mais ambiciosos estilisticamente como Rasto atrás. 